\title{
Adopting Citizen Science as a Tool to Enhance Monitoring for an Environment Agency
}

\author{
Erin Roger, Eren Turak and Patrick Tegart
}

The New South Wales' (NSW) Government of Australia through the Office of Environment and Heritage $(\mathrm{OEH})$ has recognised the potential of citizen science for improving environmental outcomes for NSW. Citizen science can achieve two primary objectives for government: (1) expanding the potential for information collection, analysis, and curation; and (2) engaging and motivating the community who become involved. It also has the potential to increase inter-agency collaboration to achieve state and national large-scale policy objectives. In 2016 OEH made a firm commitment to citizen science by creating a position focused on citizen science and releasing a three-year citizen science strategy. The vision of this strategy is to "drive a new era of public participation in science by developing collaborative projects that support decision-making and are engaging for the public." The emphasis on a real contribution by citizen scientists to decision-making is a critical and distinguishing part of this vision. To support this, OEH has a position statement defining the standards adhered to by OEH citizen science projects. Here we detail how the staff involved achieved agency support and endorsement for its citizen science program. We describe pilot studies implemented to demonstrate how citizen science can augment environmental monitoring and enhance the way $\mathrm{OEH}$ interacts with its citizen science community. We outline organisational challenges (e.g., data management, agility, and branding) that we encountered when establishing a citizen science program as well as the steps undertaken to address these challenges. We close by discussing some of the ways government can use citizen science as part of Australian policy delivery, and articulate ways in which the government can provide ongoing support to citizen science.

Keywords: government; citizen science; strategy; decision-making; barriers

\section{Introduction}

The Office of Environment and Heritage (OEH) is the Australian state of New South Wales' (NSW) environment and heritage government agency. NSW is Australia's most populous state and has a geographic area of more than 800,000 square kilometers. OEH employs approximately 3,000 staff spread across seven functional divisions (e.g., National Parks, Policy, and Science Divisions) with office locations spread throughout the state representing a geographically dispersed workforce in addition to vastly different functions and core remits of staff. The primary responsibilities of the agency are to protect and conserve NSW's biodiversity, landscapes, and cultural heritage. This includes ongoing monitoring and assessments to build the knowledge base and better understand the condition of the natural environment.

Early in 2015, when a new statewide environmental monitoring strategy was being developed, scientists in

NSW Office of Environment and Heritage, AU

Corresponding author: Erin Roger (erin.roger@csiro.au)
OEH's Science Division recognised the potential of citizen science as a monitoring tool that could enhance capacity to meet OEH's vast data and information requirements. The scientists understood that the data and information challenges of statewide monitoring could in part be met by investing in citizen science as a means to obtain scientific information at scales and resolutions unattainable by government agencies alone (Pocock et al. 2018). They also knew that by investing in citizen science, OEH could have the added benefit of engaging the public in science. They recognised citizen science as a tool that could help meet growing public demand to participate in environmental science while making a meaningful contribution to scientific knowledge.

Below we have outlined the sequential steps that the scientists took to establish OEH's Citizen Science Program (Figure 1). We follow this with an outline of organisational challenges encountered when establishing the citizen science program and the steps undertaken to address the challenges. We conclude by discussing some of the ways that citizen science aligns with current state and federal government initiatives, and if properly resourced, could help deliver on some broad policy objectives. 


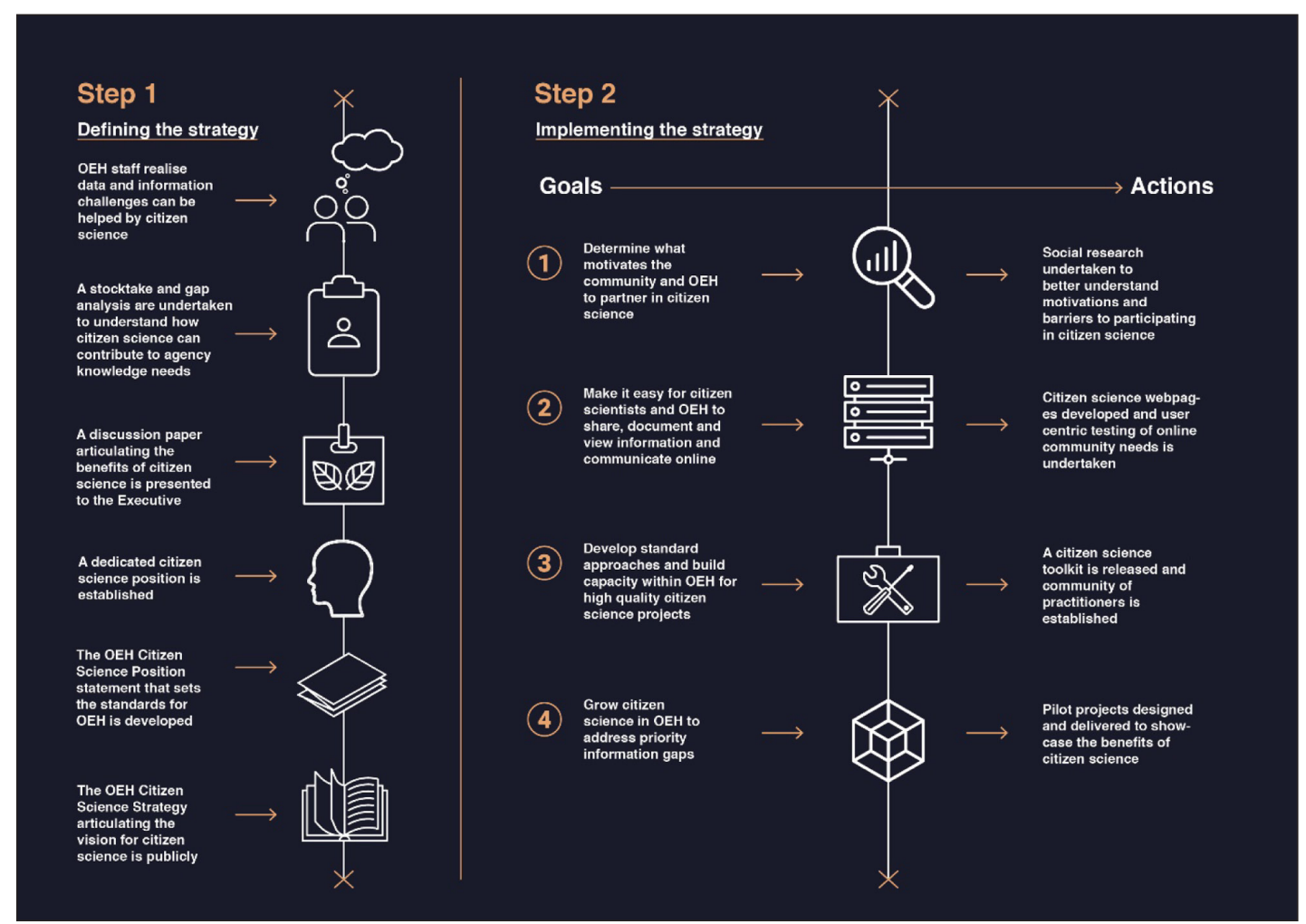

Figure 1: Steps taken to implement the OEH Citizen Science Program.

\section{Establishing a Citizen Science Program Understanding the current state of citizen science in $\mathrm{OEH}$}

As a first step to implementing a citizen science program in $\mathrm{OEH}$, the interested scientists took stock of existing $\mathrm{OEH}$ projects to understand the existing breadth of projects and experience in the agency. Projects identified were diverse, including those involving citizens in monitoring wind erosion and dust; local koala populations; and invasive weeds. However, at the time, there was no cohesive approach to citizen science in $\mathrm{OEH}$; there was no easy way to take stock of current citizen science projects, to find out how many participants they included, to understand how they aligned to government priorities, nor to understand how the information was being stored or used.

Having a clear purpose and understanding of how a citizen science program within $\mathrm{OEH}$ could fill agency knowledge gaps was crucial for positioning citizen science within the agency and obtaining executive-level support. To achieve this, gaps were identified through knowledge audits in the areas where citizen science potentially could make a meaningful contribution. These areas included: Mapping of habitats and ecosystems; abundance and distribution of threatened, iconic, or keystone species (both terrestrial and aquatic), particularly fauna; abundance and distribution of pests; extent of endangered ecological communities; extent and condition of native vegetation; air quality; and soil mapping.

\section{Gaining support for a citizen science program}

After completing the stocktake and knowledge audits, the scientists prepared an internal discussion paper for the $\mathrm{OEH}$ Executive outlining the potential of citizen science, its current status, and the steps needed to implement a program. After presenting the paper, it was agreed via internal discussions at an agency level that there was value in investing in developing an integrated citizen science program. It also was agreed that the OEH Citizen Science Program would focus on the enhancement of monitoring programs and exploration of how citizen science could enable an increase in the volume of data collected and processed. OEH was considered well placed to lead on citizen science given its clear requirement for environmental data and information and strong mandate to use this information to inform policy.

\section{Establishing a dedicated citizen science position}

As the first step in adopting citizen science formally, a dedicated position was created to help deliver and grow citizen science for the agency. The position was located in the Science Division of OEH, to firmly embed science and the importance of rigour in citizen science. The staff position was established with four main roles: (1) to provide expert advice to those leading citizen science projects within $\mathrm{OEH}$ in the scientific design and evaluation of programs; (2) to build strategic alliances with external organisations and practitioners to develop long-term partnerships and access to external expertise in citizen science; (3) to establish and foster a citizen science community of practitioners in $\mathrm{OEH}$ to ensure a coordinated approach across the organisation and the sharing of best practices in learning and appropriate use of technology; and (4) to carry out strategic research in citizen science. Strategic research consisted of targeted initiatives, such as conducting social research, and designing flagship projects that tested the rigour of citizen scientist projects. 


\section{Public release of OEH's Citizen Science Policy and Strategy}

Concerns were raised at the agency level that OEH needed a document that clearly outlined when and why $\mathrm{OEH}$ would partner, commission, or undertake citizen science. The absence of such a document could leave the organisation exposed to groups or individuals wanting support for citizen science that was not aligned to agency knowledge priorities or had sufficient rigour. To address this, the $\mathrm{OEH}$ Citizen Science Position Statement (OEH 2016a) was prepared. The aim of this statement was to ensure that all citizen science undertaken or commissioned by $\mathrm{OEH}$ met consistent standards, generated information that supported OEH knowledge priorities, and was beneficial to the community by meeting its needs and interests. The statement was intended to help clarify when and why $\mathrm{OEH}$ would partner in citizen science, and was released in parallel with its citizen science strategy.

The OEH Citizen Science Strategy (OEH 2016b) supported the Position Statement by delivering a clear mandate and direction for citizen science in the organisation. The Strategy set the vision for citizen science that was to "drive a new era of public participation in science by developing collaborative projects that support decision-making and are engaging for the public." The emphasis on a real and engaging contribution by citizen scientists was a critical and distinguishing part of this vision.

Four primary goals identified in the strategy were designed to achieve the vision: (1) Determine what motivates the community and OEH to partner in citizen science; (2) Make it easy for citizen scientists and OEH to share, document, and view information and communicate online; (3) Develop standard approaches and build capacity within $\mathrm{OEH}$ for high-quality citizen science projects; and (4) Grow citizen science in OEH to address priority information gaps (Figure 1). These goals underpinned annual planning of OEH activities related to citizen science and evaluation of the outcomes of these activities. On completion of the strategy (June 2019), OEH will evaluate the program's primary outcomes described in the strategy, which are to: (1) Build capacity for citizen science in OEH and within the community; (2) Ensure citizen science provides scientifically rigorous data and information; and (3) Ensure the community is active and engaged in science and recognised as a partner. The benefit of this approach is that it will allow OEH to examine the program's overall strengths and weaknesses and to better evaluate the value of citizen science in meeting identifed goals.

\section{Implementing the OEH Citizen Science Strategy Goal 1 - Determine what motivates the community and $\mathrm{OEH}$ to partner in citizen science}

The Strategy identified the need for social research to understand NSW community motivations and barriers to participating in citizen science. OEH staff also wanted to test which of the topic areas listed in the knowledge gap audits would interest potential community participants. Social research results revealed that the term citizen science was not widely known and understood, but once explained, the concept was broadly appealing as a way for people to give back to their community or to society more broadly (Roger et al. 2019). Other motivations to participate in citizen science included provision of a clear understanding of both time commitment and task(s) required of participants. Key barriers to participating in citizen science were identified such as time commitment, a lack of confidence in contributing to science and research, and a lack of awareness about what institutions undertake scientific research. The outputs of this research reshaped how OEH scoped projects, communicated citizen science, and recruited citizen scientists.

Goal 2 - Make it easy for citizen scientists and $\mathrm{OEH}$ to share, document, and view information and communicate online

The first step to improving how OEH engaged and communicated with citizen scientists online was to create web pages that profiled the OEH Citizen Science Program, allowing the community to easily find projects in which they could participate, and also to register interest in participating in projects. Projects were broken into thematic groupings such as threatened species, land, soil, and freshwater projects. Since the citizen science webpages were published in 2016, the number of unique page views has increased by $30 \%$ on an annual basis, and they are now some of Science Division's most visited pages. In addition, more than 250 people have filled out a simple online form registering interest in participating in projects aligned to their interests and expertise.

Updating webpages was the initial first step, however, OEH staff understood that they still had no easy way of measuring how many people were participating in projects, the frequency, and the participants' satisfaction. The result was both fragmentation of data and the community, and no consistent experience for citizen science participants. This was because OEH lacked a digital relationship with its citizen science community and had no effective mechanism to enhance quality assurance and quality control over the program. User-centric design work that tested what would motivate the community to interact with $\mathrm{OEH}$ online was conducted. Results from the user-centric design study indicated that $\mathrm{OEH}$ needed to design a platform that allowed citizen scientists to explore, join, and follow projects; aggregate and visualise data; and create profiles to showcase their interests. The platform also had to allow the community to have insight into how their contributed data and information are used by OEH. OEH's solution to address the findings from the user-centric design work is detailed further in the organisational challenges section.

\section{Goal 3 - Develop standard approaches and build capacity within $\mathrm{OEH}$ for high-quality citizen science projects}

With the predicted growth in citizen science across the agency, there was a need for consistency in delivery and access to best practice standards. It was recognised early on that there would be reputational and delivery risks with poorly designed and implemented projects, in particular a risk in return on investment and the quality of data 
collected. Moreover, staff had made it known that there were a lack of resources and knowledge-sharing capacity to ensure best practice in project delivery, data collection, and volunteer engagement across the program. To address these risks, a public citizen science toolkit was developed and launched. The toolkit (OEH 2018) is intended to assist with scoping and coordination of best practice citizen science projects. The toolkit is broken down into five core sections: Define, engage, collect, create, and manage. Each section outlines key steps and considerations that are essential to ensure that projects are feasible and sustainable and that they collect data that meet the standards detailed in the OEH Citizen Science Position Statement (OEH 2016a).

To further build a community of practitioners within the agency, OEH staff established a dedicated citizen science group on its internal social media platform, "Yammer." This group has increased the exposure, understanding, and transparency of the value of citizen science to the agency, and has been a successful way of disseminating information and promoting the citizen science work within OEH internally. More than 300 members share journal articles, courses and training, media, best practice, and project information. Importantly, in a large organisation such as $\mathrm{OEH}$, the group has helped to prevent duplication of initiatives and has encouraged collaboration on projects.

\section{Goal 4 - Grow citizen science in OEH to address priority information gaps}

To build the capacity for citizen science in OEH and to demonstrate methods that staff could adopt to include a citizen science element in projects, a series of pilot projects was designed that could test efficiencies and target identified knowledge gaps. Four of these pilot projects are detailed below.

\section{Building collaborations with the education sector}

The potential benefits of collaboration between education and citizen science has been widely reported in literature (Kobori et al. 2015; Saunders et al. 2018). However, concern remained in OEH about the value of student contribution to meaningful scientific results. To showcase the benefits of working with school students, an initiative was designed to increase collaboration between scientists and educators through citizen science and to test the value of involving students in research. Each year since this pilot project's inception in 2015, six scientists work with a local school to collaborate on an ecology-based citizen science project. Student involvement in the research has varied each year, but has ranged from generating hypotheses, helping to construct study materials, taking measurements/observations during the study period, and analysing the data. Benefits for students and teachers involved have included increased understanding of the scientific method and involvement in a "real" scientific experiment. Benefits for scientists include access to study areas typically off-limits (i.e., school grounds), increased spatial scales (the study is replicated across six schools across Australia), site-based replication, and building collaborations with the education sector. To date, results have been published from one of the projects (Saunders et al. 2018) outlining constraints and considerations when working with students to increase confidence in results, with more publications from the initiative currently under review. This initiative is starting to gain traction both internally and externally, with interest now shown in exploring how scientists can further engage schools in their research.

Testing the utility of photopoints and remote camera image curation

Each year OEH collects thousands of images as part of its environmental monitoring program. This information is required to inform major programs and legislation, such as its threatened species program, coastal monitoring program, and native vegetation protection legislation. Image collection projects include collecting reference images at plot-based and site-based scales to assist in qualitative assessments of vegetation condition or shoreline change, documenting temporal changes, and validating field data. Remote camera images are used to monitor the health of threatened species populations or to monitor trends in abundance of species. Involving citizen scientists can be a popular means of engaging people to contribute to the development of long-term and frequent observation datasets (Swanson et al. 2015; Hsing et al. 2018). However, uncertainty around the value of public provision of images and participation in curation remained. OEH designed several pilot initiatives to involve the public in monitoring using smartphone images and in remote camera image curation. To date, these projects have been a huge engagement success, and results from our coastline monitoring project "CoastSnap" have demonstrated the scientific value of citizen photopoint monitoring (Harley et al. 2019). Accuracy results in terms of species identification from remote camera images have varied widely. $\mathrm{OEH}$ is working to improve this process through adjustment to "how to" instructions and modifications to the platform itself. These improvements should lead to being able to demonstrate the value to the agency more fully, not only as a mechanism to engage the public in science, but also to achieve cost efficiency by reducing staff time required to curate images.

Local scale community monitoring

In 2018, scientists in OEH established a citizen science project in the form of a community-based biodiversity monitoring program in the Indigenous managed Rick Farley Reserve, located in the western part of the state. The program was designed to engage Indigenous community members, OEH staff, school teachers, and students in fauna monitoring. The monitoring program combines loosely structured day and night searches across the reserve as well as continuous video recording at seven locations designed to generate data comparable to pitfall trapping. To date, more than 2,000 bird, reptile, and mammal sightings have been recorded. In early 2019, acoustic monitoring commenced at four selected locations. Community members and school students are able to fully participate in monitoring activities, including processing of footage obtained through video recording. An app for mobile devices was developed to facilitate species sightings at the reserve and to share biodiversity observations. This app 
will be central to engagement of Indigenous communities in biodiversity monitoring in the region, and serves as a case study of the benefits of engaging the community in biodiversity monitoring. This approach explicitly connects biodiversity condition to management actions and is an effective way of engaging the community in science. The work detailed above will inform threatened species and threatened ecological community management at the reserve scale by involving the community in management activities based on their observations.

Testing the difference between citizen science and professionally collected data

Facilitating programs that encourage community-based monitoring (as above) or investing in research to test the rigour of existing community monitoring data represents huge potential to enhance OEH's information base. As an agency, OEH invests in large-scale professional monitoring programs such as water quality and bird monitoring. There are also longstanding community programs and groups that have been engaged in monitoring and generating data, i.e., birding and river monitoring groups. However, concerns with existing community data were raised by $\mathrm{OEH}$ scientists, who stressed the need for confidence in the citizen science data, given its use in supporting legislation and regulation. To test the difference between data collected by professional scientists and by citizen scientists, studies were set up where a professional scientist collected data in parallel with citizen scientist collected data (Figure 2). Preliminary results from both birding and water quality trials suggest that the data are comparable, however, these studies are still running as of September 2019. Indeed, building the confidence around citizen science in general takes time, so long-term investment is often required to help build this certainty. Nonetheless
OEH recommends agencies set up comparison studies such as these to help provide assurances over data quality, modification of methodology (if required), and eventual broader acceptance of citizen science-generated data.

\section{Organisational Challenges Encountered in Implementing a Citizen Science Program}

The initial OEH citizen science project stocktake and the annual evaluations of the OEH Citizen Science Strategy, identified three ongoing challenges for implementing a successful citizen science program in OEH. These are: (1) data quality and management; (2) maintaining pace with the growth of citizen science; and, (3) communication and branding. We have detailed these challenges and steps taken to address them below.

\section{Data quality and management}

Similar to the primary policy challenge reported in Hyder et al. (2015), the main issue that OEH scientists identified was concerns about the quality of citizen science data in terms of accuracy, appropriate metadata, and ease of access. They recognised that efficient sharing of citizen science data required systems that could support the providers and custodians of data and would have the capacity to aggregate data. They also understood the need for data to be highly useable, and felt that the addition of data discovery, visualisation, and analytical tools were crucial to the program's success. Presently, $\mathrm{OEH}$ can receive community data through a number of web portals and applications, although these are not necessarily connected or intuitive. To address this, OEH used the results of the user-centric testing described earlier and undertook steps to modify the way that data are input, stored, and output so that the public can receive feedback and data can be used and interpreted. To do this, OEH is partnering with the NSW

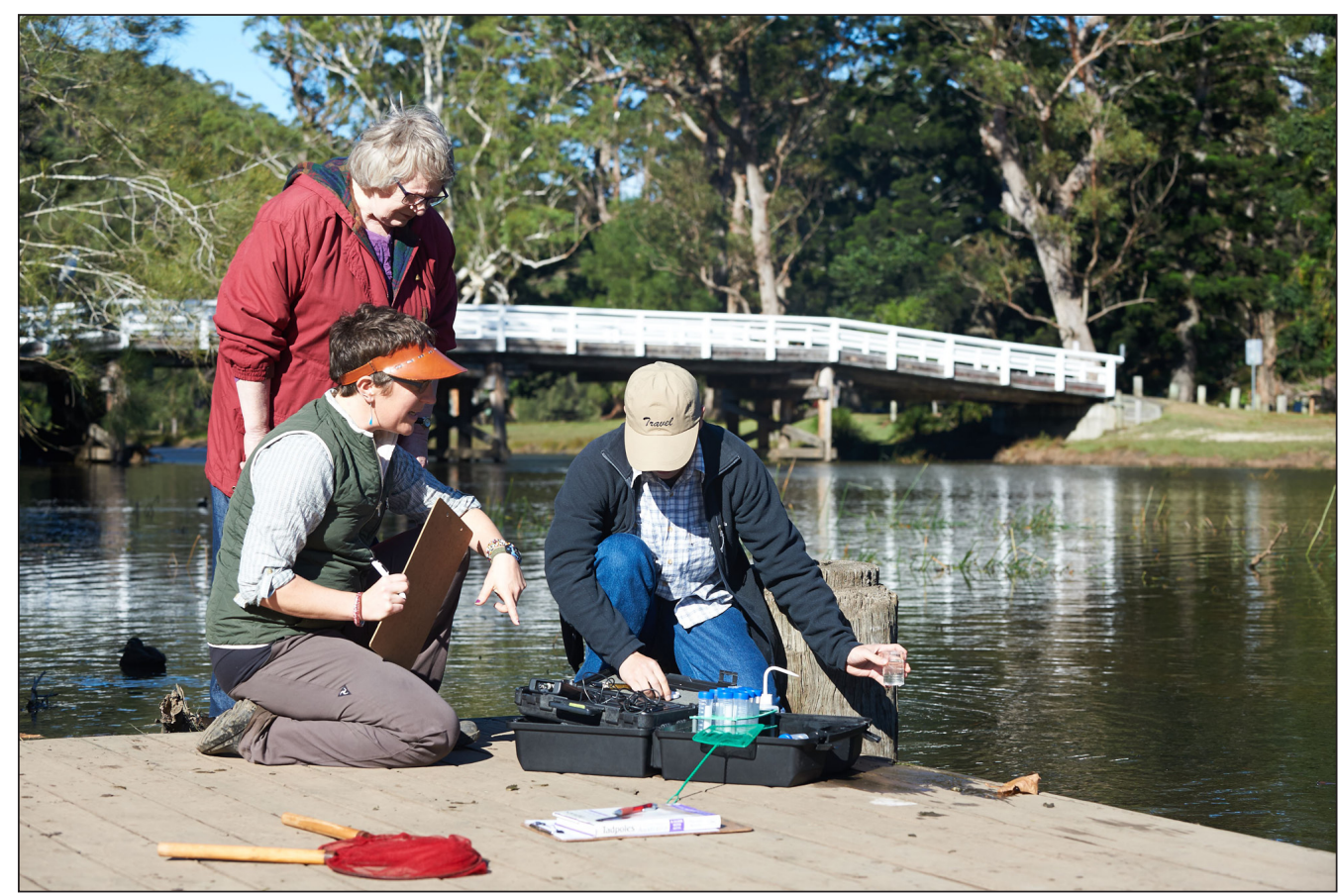

Figure 2: OEH set up a number of studies including several on water quality to test the differences between data collected by professional scientists and data collected by citizen scientists. Photo: Peter Robey. 
Government's Sharing and Enabling Environmental Data (SEED) portal, which (when fully functional) is intended to be the one-stop shop to access and view environmental data. SEED will enhance the ability of government scientists to use the data in the portal, have oversight of who contributed the data, and disseminate their findings to a broader audience. It also will provide an easier-to-use portal for citizen scientists to input and visualise their data. The vision is to aggregate effort by connecting the NSW citizen science community to each other, to projects, and to data. In doing so, OEH hopes to profile the potential of citizen science data as a more trustworthy and efficient source of information.

\section{Maintaining pace with the growth of citizen science} An additional challenge that OEH staff identified is the need to keep abreast of the rapid interest and uptake of citizen science. Citizen science (and the technology that supports it) is quickly advancing and maturing. However, $\mathrm{OEH}$ is often unable to maintain pace with these advancements and adopt new approaches. The reasons behind this are not unique to $\mathrm{OEH}$, but likely are symptomatic of larger organisations, with approvals, legacy platforms, and branding constraints as some of the reasons for the lack of agility. For example, the timing required to deliver on citizen science can be out of sync with the timing of other programs and projects that the citizen science initiative is dependent upon. Updating webpages can be held up due to other more urgent agency processes and priorities. OEH staff have tried to counter these issues by partnering with other institutions that are more agile and have the existing platforms and systems required. The benefit of this approach has been the creation of strong partnerships, sharing of expertise, and greater outreach potential. The drawback of these partnerships can be reduced or lack of visibility with the community in terms of who is leading citizen science initiatives. For example, when $\mathrm{OEH}$ uses a photo curation platform to run a project, that project is one of many operating on a platform that is clearly branded and owned by another organisation. The resulting lack of visibility can hinder OEH's ability to build trust with the community directly involved in its projects, which is important to sustain relationships and attract new project participants. A further challenge is in community relationship management and achieving consistent messaging across various citizen science and volunteer programs when they are managed in separate areas. The need for intra-agency transparency has meant that staff communicate actively (e.g., via Yammer posts, biannual newsletter, workshops) so that citizen science initiatives and partnerships are known across OEH in order to avoid duplication and multiple approaches to the same issues and collaborators.

\section{Communication and branding}

$\mathrm{OEH}$ is a large organisation with social and media content provided across a breadth of programs. As a result, $\mathrm{OEH}$ staff found that they were unable to promote certain citizen science projects at the timing and frequency desired. This created promotional and recruitment barriers for projects and missed opportunities to celebrate citizen scientist effort. Additionally, consistent branding of citizen science throughout OEH also posed some challenges. Some projects branded as citizen science did not meet criteria to be citizen science, while others that did were not appropriately tagged. This created a risk to the "citizen science" brand of OEH. Without a consistent approach and understanding of the components of citizen science (and the benefits that may arise), there was risk to impeding the uptake of citizen science internally and sending mixed messages externally. To date, branding and communication remain an ongoing challenge for the Citizen Science Program. To help overcome some of the branding and communication challenges, OEH staff have developed key message documents and work closely with other areas of the agency to clearly communicate the goals and objectives of the program. Changes in government agency names are also an ongoing challenge for brand recognition, so going forward, OEH will brand its citizen science program rather than relying on agency name recognition.

\section{Government Can Use Citizen Science as Part of Australian Policy Delivery}

The value of citizen science has been recognised widely by national governments in Europe and the United States as a way to deliver evidence, resources, and improved reputation (Hyder et al. 2015). However, to date, Australia at both federal and state levels has been slower to formally recognise the potential. Crucially, properly mobilised citizen science can help to deliver on many existing Australian national and state government initiatives, such as open government, open data, and open science. Opportunities also exist in Australia for both state and federal governments to leverage increased program funding that can benefit multiple portfolios (e.g., health, education, Indigenous affairs, heritage, the environment) through citizen science.

There are existing Australian national and state policies where citizen science can play a role in delivery if supported or organised; these include the National Innovation \& Science Agenda (Commonwealth of Australia 2015), which advocates for e-infrastructures and standards for discovering and aggregating data; The NSW Government Open Data Policy (DFSI 2016), for which government could harness the digital potential of the citizen science "crowd" to engage with government data; and Closing the Gap (Commonwealth of Australia 2018), for which there is potential to tap into and expand existing Indigenous citizen science projects that encourage knowledge exchange between Indigenous communities and scientists to help manage ecological systems on country. Citizen science also could help to achieve the objectives in the NSW Digital Transformation Strategy (DFSI 2016), which encourages a digital approach to more open and collaborative data sharing. Recently, work has been under way led by the Citizen Science Global Consortium and other complementary initiatives (Chandler et al. 2017) to collaborate on a global scale to help advance citizen science for a sustainable world and to demonstrate how citizen science can be used to address the United Nation's Sustainable Development Goals (SDGs). These collaborations can help to support Australian federal and state agencies in achieving SDG targets (Fritz et al. 2019). 
Despite missed opportunities to mobilise citizen science to achieve policy objectives, all levels of government in Australia are starting to play an essential role in helping to increase the visibility and credibility of citizen science. Support by state and national Chief Scientists has been integral in helping to elevate the profile of citizen science. In 2015, then Australian Chief Scientist (Ian Chubbs) supported the delivery of an occasional paper "Building Australia through citizen science" (Pecl et al. 2015), which articulated opportunities and advantages to citizen science in Australia. Recently, the current Chief Scientist of Australia spearheaded the integration of the Australian Citizen Science Association's project finder with the STAR portal, which is the national directory of Australian science, technology, engineering, and mathematics (STEM) activities. Most recently, the Queensland Chief Scientist led the development of a state strategy for citizen science (Office of the Chief Scientist 2018). The announcement of the strategy was accompanied by grants to stimulate growth and collaboration among citizen science practitioners. Crucially in 2017, the federal government released more than six million dollars in funding towards a grant program that aimed to increase opportunities for the public to engage in science through citizen science. However, the grant round also demonstrated the huge demand and interest for funding in citizen science, as more than 300 grant applications were received, with 13 receiving funding.

\section{Conclusions}

Since the inception of the OEH Citizen Science Strategy, OEH has taken major steps towards establishing citizen science as an important part of helping to deliver on its core responsibility of protecting and conserving the state's biodiversity. Integration of citizen science into $\mathrm{OEH}$ benefited from a stocktake and knowledge gap anal- ysis to showcase benefits of a coordinated citizen science approach; a clear commitment from OEH Executive leadership to support citizen science through resources and policy documents; social research to guide programatic delivery; improved access to citizen science information online; development of standard approaches to citizen science; and pilot studies to demonstrate the value proposition to OEH staff (Figure 1). As the credibility of the citizen science approach grows within the $\mathrm{OEH}$, so too has the recognition that it can achieve its two primary objectives for the agency: (1) vastly expand the potential for information collection, analysis, and curation; and (2) engage and motivate the community who become involved.

Developing a public facing policy and strategy was the most important factor in establishing the program and was an important step to position $\mathrm{OEH}$ as a leader in this space in Australia. In doing so, OEH staff established a process whereby OEH can measure success and impact of the citizen science program to be able to justify continued investment. It is important to recognise that it takes time to adequately measure program-level outcomes; so upfront and ongoing investment is required to provide stability and continuity to the program. Indeed, the diffusion of science into policy has been recognised as incremental (Rosen 2018), so while the potential for citizen science to provide insight and evidence that informs policy exists, it is often difficult to demonstrate this causal link within short periods of time. To fulfil this potential, citizen science will need to continue to meet the needs of participants, practitioners, and decision-makers. The future of citizen science lies in connecting people, projects, and data, and drawing on co-creation to facilitate mutual agreement. Only then will $\mathrm{OEH}$ fully realise its vision of driving a new era of public participation in science by developing collaborative, engaging projects that support decision-making (Figure 3).

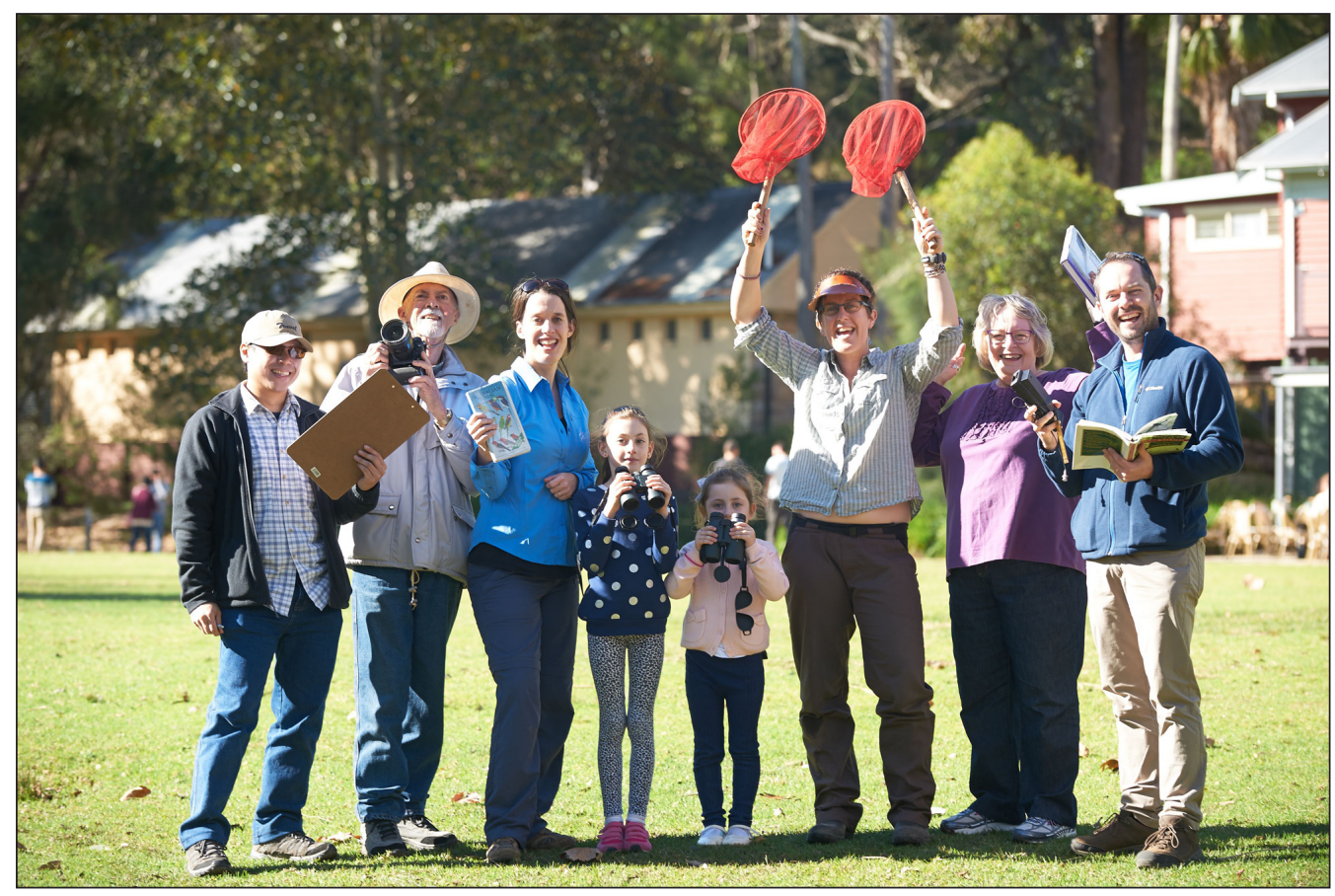

Figure 3: OEH's vision is to drive a new era of public participation in science by developing collaborative, engaging projects that support decision-making. Photo: Peter Robey. 
Going forward, there is cause and opportunity for all levels of government in Australia to invest more in citizen science to increase its impact on public sector policies and practices. Although institutional barriers do exist, with governments' commitment for evidence to inform policy and decision-making, the value of investing in citizen science as a tool to scale agency data and information requirements is clear. Citizen science aligns with Australian state and federal strategies and policies, and if mobilised and supported, can help to achieve ambitious targets around encouraging science education, open data, and discovery. It also has the potential to break down silos between government departments by encouraging collaboration between the environment and health, education, and environment, for example. Government is well positioned to help provide the infrastructure required to improve the standards and rigour around citizen science. Furthermore, it should play a crucial role in helping to connect and promote networks by linking local, federal, and global initiatives to encourage greater collaboration, participation, and promotion of results. Looking ahead, meeting global scale challenges will require international collaboration and integrated responses. Citizen science has tremendous potential to help provide cross-cutting solutions. Government can help by designing and adopting global citizen science approaches and shared methodologies to begin to tackle these shared challenges.

\section{Competing Interests}

All authors at the time of writing were employed by the NSW Office of Environment and Heritage and are either currently or formerly directly involved in the development of the citizen science program. While this gives the authors unique insight into the program, they recognise that this also could result in biased views concerning its establishment and success.

\section{References}

Chandler, M, See, L, Copas, K, Bonde, AMZ, López, BC, Danielsen, F, Legind, JK, Masinde, S, Miller-Rushing, AJ, Newman, G, Rosemartin, A and Turak, E. 2017. Contribution of citizen science towards international biodiversity monitoring. Biological Conservation, 213: 280-294. DOI: https://doi. org/10.1016/j.biocon.2016.09.004

Commonwealth of Australia. 2015. Department of Prime Minister and Cabinet National Innovation \& Science Agenda Report 2015. Available at: https:// www.industry.gov.au/data-and-publications/nationalinnovation-and-science-agenda-report [last accessed 25 October, 2018].

Commonwealth of Australia. 2018. Department of the Prime Minister and Cabinet Closing the Gap Prime Minister's Report 2018. Available at: https://closingthegap.pmc.gov.au/sites/default/files/ctg-report-2018. pdf?a=1 [last accessed 25 October, 2018].

Department of Finance, Services and Innovation. 2016. Digital NSW Designing our Digital Future. Available at https://www.digital.nsw.gov.au/sites/
default/files/DigitalStrategy.pdf [last accessed 25 October, 2018].

Department of Finance, Services and Innovation. 2016. NSW Government Open Data Policy. Available at: https://www.digital.nsw.gov.au/sites/default/files/ NSW_Government_Open_Data_Policy_2016.pdf [last accessed 25 October, 2018].

Fritz, S, See, L, Carlson, T, Haklay, M, Oliver, JL, Fraisl, D, Mondardini, R, Brocklehurst, M, Shanley, LA, Schade, S, Wehn, U, Abrate, T, Anstee, J, Arnold, S, Billot, M, Campbell, J, Espey, J, Gold, M, Hager, G, He, S, Hepburn, L, Hsu, A, Long, D, Maso, J, McCallum, I, Muniafu, M, Moorthy, I, Obersteiner, M, Parker, AJ, Weissplug, M and West S. 2019. Citizen science and the United Nations Sustainable Development Goals. Nature Sustainability, 2: 922-930. DOI: https://doi.org/10.1038/s41893-019-0390-3

Harley, MD, Kinsela, MA, Sánchez-Garcia, E and Vos, K. 2019. Shoreline change mapping using crowdsourced smartphone images. Coastal Engineering, 150: 175-189. DOI: https://doi.org/10.1016/j.coastaleng.2019.04.003

Hsing, P, Bradley, S, Kent, VT, Hill, RA, Smith, GC, Whittingham, MJ, Cokill, J, Crawley, D, Volunteers, M and Stephens, PA. 2018. Economical crowdsourcing for camera trap image classification. Remote Sensing in Ecology and Conservation, 4(4): 361-374. DOI: https://doi.org/10.1002/rse2.84

Hyder, K, Townhill, B, Anderson, LG, Delany, J, Delany, J and Pinnegar, JK. 2015. Can citizen science contribute to the evidence-base that underpins marine policy? Marine Policy, 59: 112-120. DOI: https://doi. org/10.1016/j.marpol.2015.04.022

Kobori, H, Dickinson, JL, Washitani, I, Sakurai, R, Amano, T, Komatsu, N, Kitamura, W, Takagawa, S, Koyama, K, Ogawara, T and Miller-Rushing, AJ. 2015. Citizen science: a new approach to advance ecology, education, and conservation. Ecological Research, 31: 1-19. DOI: https://doi.org/10.1007/s11284-015-1314-y

Office of Environment and Heritage. 2016a. Office of Environment and Heritage Citizen Science Position Statement. Available at: https://www.environment. nsw.gov.au/research-and-publications/publicationssearch/citizen-science-position-statement [last accessed 30 January 2019].

Office of Environment and Heritage. 2016b. Office of Environment and Heritage Citizen Science Strategy. Available at: https://www.environment.nsw.gov.au/ research-and-publications/publications-search/oehcitizen-science-strategy-2016-2018 [last accessed 22 November 2018].

Office of Environment and Heritage. 2018. Office of Environment and Heritage Citizen Science Toolkit. Available at: https://www.environment.nsw.gov.au/ research-and-publications/your-research/citizenscience/citizen-science-toolkit [last accessed 30 January 2019].

Office of the Chief Scientist Queensland. 2018. Queensland Citizen Science strategy. Available at: 
https://www.chiefscientist.qld.gov.au/documents/ pubs/reports-other/queensland-citizen-science-strategy.pdf [last accessed 27 January 2019].

Pecl, GT, Gillies, C, Sbrocchi, C and Roetman, P. 2015. Building Australia through Citizen Science Occasional Paper Series. In: Canberra: Australian Government Office of the Chief Scientist. Available at: http://www. chiefscientist.gov.au/2015/07/occasional-paperbuilding-australia-through-citizen-science/.

Pocock, MJO, Chandler, M, Bonney, R, Thornhill, I, Albin, A, August, T, Backman, S, Brown, PMJ, Cunha, DGF, Grez, A, Jackson, C, Peters, M, Romer Raarijaon, N, Roy, HE, Zaviezo, T and Danielsen, F. 2018. A Vision for Global Biodiversity Monitoring With Citizen Science. Advances in Ecological Research, 59: 169-223. DOI: https://doi.org/10.1016/ bs.aecr.2018.06.003

Roger, E, Patrick, T, Dowsett, R, Kinsela, MA, Harley, MD and Ortac, G. 2019. Maximising the potential for citizen science in New South Wales. Phones, Drones and People: New Approaches to Zoology. DOI: https://doi.org/10.7882/AZ.2019.023
Rosen, J. 2018. Help to shape policy with your science. Nature, 560: 671-673. DOI: https://doi.org/10.1038/ d41586-018-06038-4

Saunders, ME, Roger, E, Geary, WL, Meredith, F, Welbourne, DJ, Bako, A, Canavan, E, Herro, F, Herron, C, Hung, O, Kunstler, M, Lin, J, Ludlow, N, Paton, M, Salt, S, Simpson, T, Wang, A, Zimmerman, N, Drews, KB, Dawson, HF, Martin, LWJ, Sutton, JB, Webber, CC, Ritchie, AL, Berns, LD, Winch, BA, Reeves, HR, McLennan, EC, Gardner, JM, Butler, CG, Sutton, EI, Couttie, MM, Hildebrand, JB, Blackney, IA, Forsyth, JA, Keating, DM and Moles, AT. 2018. Citizen science in schools: Engaging students in research on urban habitat for pollinators. Austral Ecology, 43: 635-642. DOI: https://doi.org/10.1111/aec.12608

Swanson, A, Kosmala, M, Lintott, C, Simpson, R, Smith, A and Packer, C. 2015. Snapshot Serengeti, high-frequency annotated camera trap images on 40 mammalian species in an African savanna. Scientific Data, 2: 150026. DOI: https://doi. org/10.1038/sdata.2015.26

How to cite this article: Roger, E, Turak, E and Tegart, P. 2019. Adopting Citizen Science as a Tool to Enhance Monitoring for an Environment Agency. Citizen Science: Theory and Practice, 4(1): 35, pp.1-9. DOl: https://doi.org/10.5334/cstp.231

Submitted: 30 January 2019 Accepted: 30 August $2019 \quad$ Published: 02 December 2019

Copyright: ( $) 2019$ The Author(s). This is an open-access article distributed under the terms of the Creative Commons Attribution 4.0 International License (CC-BY 4.0), which permits unrestricted use, distribution, and reproduction in any medium, provided the original author and source are credited. See https://creativecommons.org/licenses/by/4.0/. 